\title{
A prediction model of surgical site infection after instrumented thoracolumbar spine surgery in adults
}

\author{
Daniël M. C. Janssen ${ }^{1}$ (D) $\cdot$ Sander M. J. van Kuijk ${ }^{1} \cdot$ Boudewijn d'Aumerie $^{1} \cdot$ Paul Willems $^{1}$
}

Received: 17 July 2018 / Accepted: 31 December 2018 / Published online: 7 January 2019

(c) The Author(s) 2019

\begin{abstract}
Purpose The aim of this study was to develop and internally validate a multivariable model for accurate prediction of surgical site infection (SSI) after instrumented spine surgery using a large cohort of a Western European academic center.

Method Data of potential predictor variables were collected in 898 adult patients who underwent instrumented posterior fusion of the thoracolumbar spine. We used logistic regression analysis to develop the prediction model for SSI. The ability to discriminate between those who developed SSI and those who did not was quantified as the area under the receiver operating characteristic curve (AUC). Model calibration was evaluated by visual inspection of the calibration plot and by computing the Hosmer and Lemeshow goodness-of-fit test.

Results Sixty patients (6.7\%) were diagnosed with an SSI. After backward stepwise elimination of predictor variables, we formulated a model in which an individual's risk of an SSI can be computed. Age, body mass index, ASA score, degenerative or revision surgery and NSAID use appeared to be independent predictor variables for the risk of SSI. The AUC was 0.72 (95\% CI 0.65-0.79), indicating reasonable discriminative ability.

Conclusions We developed and internally validated a prediction model for SSI after instrumented thoracolumbar spine surgery using predictor variables of standard clinical practice that showed reasonable discriminative ability and calibration. Identification of patients at risk for SSI allows for individualized patient risk assessment with better patient-specific counseling and may accelerate the implementation of multi-disciplinary strategies for reduction of SSI.
\end{abstract}

Graphical abstract These slides can be retrieved under Electronic Supplementary Material.

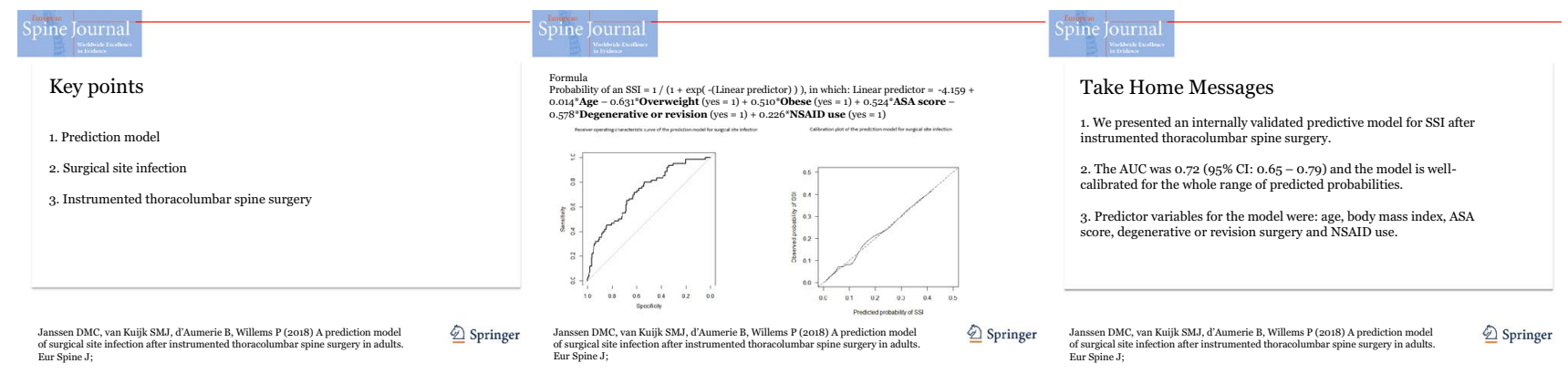

Keywords Surgical site infection · Instrumented spine surgery · Prediction model · Thoracolumbar · Logistic regression · Cohort study

Electronic supplementary material The online version of this article (https://doi.org/10.1007/s00586-018-05877-z) contains supplementary material, which is available to authorized users.

Extended author information available on the last page of the article

\section{Introduction}

Surgical site infection (SSI) is one of the most serious complications after spine surgery with potentially devastating consequences such as failure of fixation, osteomyelitis, 
pseudarthrosis, increased length of hospital stay, mortality, unfavorable surgical outcome and associated health care costs [1-5]. Within the field of orthopedic surgery, a relatively high incidence of SSIs is observed after spine surgery: up to $12 \%$ depending on diagnosis, surgical approach, use of spinal instrumentation and the complexity of the procedure [6-8]. SSIs can be both difficult to diagnose-as there is no pathognomonic sign or symptom to accurately indicate its presence-and difficult to treat. One or more operative debridements combined with prolonged antibiotic treatment may be necessary to treat the infection $[1,9,10]$. With the rise in prevalence of antibiotic-resistant organisms, the treatment of SSI has become even more difficult, and therefore, the prevention of SSI is a matter of utmost importance [11].

Prior research has identified several factors associated with an increased risk of SSI after spine surgery, e.g., advanced age, revision surgery, obesity, diabetes, smoking, high amount of intraoperative blood loss and prolonged duration of surgery $[6,7,12-14]$. These risk factors are usually reported as relative risks (RR) or odds ratios (OR). However, these RRs and ORs are measures of association and are not sufficient to estimate an individual's personal risk of SSI given a combination of these factors.

Combining risk factors into a prediction model is an appropriate tool to be used for preoperative patient counseling when evaluating the individual risk of SSI after spinal surgery. Estimating an individual's risk of SSI may help identify high risk patients, thus optimizing patient selection with possible prevention of the devastating consequences and associated outcomes of an SSI after surgery [1].

Lee et al. developed a prediction model for SSI after spine surgery based on the patient's comorbidity profile and invasiveness of surgery by using a prospectively collected registry for all surgical spine patients at University of Washington and Harborview Medical Center consisting of 1532 patients having instrumented and non-instrumented spinal surgery [12]. However, external validation of the prediction model showed poor predictive performance in a large cohort of patients undergoing instrumented thoracolumbar spine surgery in an academic spine setting [15].

The aim of this study was to develop and internally validate a multivariable prediction model for accurate prediction of SSI after instrumented spine surgery using a large cohort of a Western European academic center.

\section{Methods}

\section{Patient population}

This was a retrospective cohort study of all instrumented spinal surgery procedures of the thoracic, lumbar and thoracolumbar spine that have been performed in adult patients
( $\geq 18$ year) in an academic referral center for spinal pathology from January 1, 1999, up to January 1, 2016. Patients diagnosed with an infection after instrumented spinal surgery elsewhere were excluded as well as patients for whom the medical files for at least up to 1 year after surgery were not available.

All operations were performed by 3 experienced orthopedic surgeons specialized in spine surgery. In select cases when neurological decompression was needed, neurosurgeons participated in the operation. All patients underwent an instrumented posterior (posterolateral or interbody) spinal fusion of the thoracic, lumbar and thoracolumbar spine, with or without an additional procedure (anterior fusion or release, spinal decompression, the removal of instrumentation, tumor resection or corpectomy/osteotomy).

Patients were followed for a minimum of 1 year after the index operation to monitor all complications and incidences of revision surgery. All complications, extensive demographics, comorbidity and surgical details were recorded by collecting data from all available electronic and paper records of the patients. The primary outcome of interest was the occurrence of SSI. The diagnosis of SSI was based on the CDC criteria (Centre for Disease Control and prevention) [16] and the Dutch national PREZIES network (prevention of hospital infections through surveillance) [17]. An SSI was considered to be deep if it presented at the site of the operation with involvement of the subfascial tissues.

\section{Predictor variables}

An often-used rule of thumb states that at least 10 events (i.e., occurrences of SSI) are needed per predictor variable that is tested in the prediction model development step [18]. When more predictor variables are added to the model, the probability of overfitting (i.e., the model predicts exceedingly worse for patients not comprised in the derivation cohort) increases. As a result, we needed to perform a pre-selection of all baseline characteristics of those that we thought would be most likely to result in an accurate prediction model. The pre-selection was based on what was already known from other studies, the distribution of the predictor in our sample, and experience in our own hospital. Using this method, we were able to reduce the initial set of potential predictor variables to 8 , i.e., age, body mass index (BMI: $\mathrm{kg} / \mathrm{m}^{2}$ ), smoking status, diagnosis, revision surgery, ASA (American Society of Anesthesiologists) physical status, surgical invasiveness index (SII) [19] and the use of nonsteroidal anti-inflammatory drugs (NSAIDs) preoperatively.

Smoking status was dichotomized into currently smoking yes or no, independent of the volume and tobacco product used. All passive smokers and ex-smokers were regarded as non-smoker. ASA physical status, a classification to assess the fitness of the patient before surgery, was coded 
according to the five-category physical status classification system of the American Society of Anesthesiologists in $1963(1=$ healthy person, $2=$ mild systemic disease, $3=$ severe systemic disease, $4=$ severe systemic disease that is a constant threat to life, $5=$ a moribund person who is not expected to survive without the operation) [20]. The surgical invasiveness index is a validated instrument with a range from 0 to 48 points, containing the sum of the following six weighted surgical components: the number of levels anterior decompressed, the number of levels anterior fused, the number of levels anterior instrumented, the number of levels posterior decompressed, the number of levels posterior fused and the number of levels and posterior instrumented. The weight of each component represents the number of vertebral levels at which each respective component has been performed [19]. A higher score means higher invasiveness. For example, in an L4-L5 posterior fusion and decompression with the use of an intervertebral cage, and posterior instrumentation, the score would be 9 (anterior fusion $=2$, anterior instrumentation $=2$, posterior decompression $=1$, posterior fusion $=2$, posterior instrumentation $=2$ ).

Diagnosis of the included patients was divided into 4 subgroups, i.e., one- or two-level degenerative disorders (with or without neurologic compromise), failed back syndrome (patients that had already undergone previous spine surgery on the same level), trauma (unstable vertebral fractures with or without neurological compression) and other (adult spinal deformity, spinal metastases/malignancy, spondylodiscitis). Nonsteroidal anti-inflammatory drugs use was defined as the daily use of NSAIDs before surgery for more than 1 week and still in use at the time of surgery.

\section{Model development}

Incomplete patient records were imputed using stochastic regression imputation, to prevent a potentially considerable loss of statistical precision and to decrease the probability of biased results when compared to using only complete patient records (see Table 1). We used predictive mean matching to generate the imputed values. After imputation, we included all potential predictor variables in a logistic regression analysis. Using stepwise backward elimination on the hypothesized predictor variables, we excluded nonsignificant predictors from this category to arrive at a more parsimonious model. As suggested by prediction modeling guidelines, we used a less strict alpha for eliminating variables from the model to prevent too early deletion of potentially important predictor variables [21]. We chose to use an alpha of 0.10 compared to the conventional 0.05 .

For continuous variables, the association is assumed to be linear. Nonlinear effects were visualized using plots and formally tested using restricted cubic splines, a regression technique that can be used to test for deviations from linearity [21]. In case of significant evidence of a nonlinear relation, the continuous variable was categorized into clinically meaningful categories.

The model's performance was quantified using measures of discriminative ability and measures of calibration. We assessed the model's ability to discriminate between those who developed SSI and those who did not by computing the area under the receiver operating characteristic (ROC) curve (AUC). This AUC can range from 0.5 (no discriminative ability) to 1.0 (perfect discriminative ability). Model calibration (i.e., agreement between predicted and observed probabilities) was evaluated by visual inspection of the calibration plot and by computing the Hosmer and Lemeshow goodness-of-fit test (HL test). A significant HL test indicates evidence against good model fit.

\section{Internal validation}

We internally validated the initial prediction model using standard bootstrapping techniques. Using results from the bootstrap procedure, we penalized the model's regression coefficients, so future predictions will be less extreme (to counter the effect of overfitting) by multiplying them with a shrinkage factor, and re-estimating the model intercept. Also, we computed the estimated optimism in the AUC. This is a measure of the likely difference in AUC when the model is applied to future patients. All analyses were performed using $\mathrm{R}$ version 3.3.3.

\section{Results}

A total of 898 participants were available for the development of the prediction model. Sixty $(6.7 \%)$ were subsequently diagnosed with SSI.

Table 1 shows a summary of baseline variables including all potential predictor variables of the whole cohort and separately for those who developed SSI and those who did not.

The restricted cubic spline regression revealed evidence of a U-shaped association between BMI and SSI instead of a linear one. Therefore, we categorized BMI into three clinically relevant subgroups: normal weight (BMI up to 25), overweight (BMI between 25 and 30) and obese (BMI over 30). The backward stepwise elimination yielded the following predictor variables: age, BMI categories, ASA physical status, degenerative or revision (versus trauma and other) and the use of NSAIDs. All other potential predictor variables were eliminated from the model because their $p$ value was higher than 0.10 .

The ROC curve of the prediction model is shown in Fig. 1. The AUC was 0.72 (95\% confidence interval [CI] $0.65-0.79)$, indicating reasonable discriminative ability. The calibration plot is shown in Fig. 2. It shows the model is well 
Table 1 Baseline characteristics of all patients included in the study

\begin{tabular}{|c|c|c|c|c|}
\hline Variable & All patients (898) & No SSI (838) & SSI (60) & $p$ value \\
\hline Age & $52.2(\mathrm{SD} 16.1)$ & $51.9(\mathrm{SD} 16.0)$ & $56.9(\mathrm{SD} 16.5)$ & 0.100 \\
\hline Gender & M 48.9\%; F 51.1\% & M 48.6\%; F 51.4\% & M 53.3\%; F 46.7\% & 0.476 \\
\hline BMI & $26.1(\mathrm{SD} 4.7)$ & $26.0(\mathrm{SD} 4.5)$ & 27.9 (SD 5.9) & 0.003 \\
\hline ASA & & & & 0.004 \\
\hline 1 & $310(34.5 \%)$ & $295(35.2 \%)$ & $15(25 \%)$ & \\
\hline 2 & $435(48.4 \%)$ & $416(49.6 \%)$ & $19(31.7 \%)$ & \\
\hline 3 & $150(16.7 \%)$ & $125(14.9 \%)$ & $25(41.7 \%)$ & \\
\hline 4 & $3(0.3 \%)$ & $2(0.2 \%)$ & $1(1.7 \%)$ & \\
\hline Diagnosis* & & & & 0.717 \\
\hline Trauma & $199(22.1 \%)$ & $181(21.6 \%)$ & $18(30.0 \%)$ & \\
\hline Adult spinal deformity & $113(12.5 \%)$ & $109(13.0 \%)$ & $4(6.7 \%)$ & \\
\hline $\begin{array}{l}\text { One- or two-level degenerative spinal } \\
\text { disorder with neurologic compro- } \\
\text { mise }\end{array}$ & $379(42.1 \%)$ & $364(43.4 \%)$ & $20(33.3 \%)$ & \\
\hline Malignancy & $42(4.7 \%)$ & $35(4.2 \%)$ & $7(11.7 \%)$ & \\
\hline Failed back surgery syndrome & $96(10.7 \%)$ & $91(10.8 \%)$ & $6(10.0 \%)$ & \\
\hline $\begin{array}{l}\text { One- or two-level degenerative } \\
\text { spinal disorder without neurologic } \\
\text { compromise }\end{array}$ & $61(6.8 \%)$ & $60(7.1 \%)$ & $3(5.0 \%)$ & \\
\hline Spondylodiscitis & $8(0.9 \%)$ & $7(0.8 \%)$ & $1(1.7 \%)$ & \\
\hline SI score & $10.3($ SD 5.9) & $10.3(\mathrm{SD} 6.0)$ & $10.1(\mathrm{SD} 5.1)$ & 0.259 \\
\hline Cardiac pathology & $49(5.5 \%)$ & $44(5.3 \%)$ & $5(8.3 \%)$ & 0.310 \\
\hline Diabetes & $73(8.2 \%)$ & $66(7.9 \%)$ & $7(11.6 \%)$ & 0.323 \\
\hline Rheumatic disease & $20(2.2 \%)$ & $17(2.0 \%)$ & $3(5.0 \%)$ & 0.132 \\
\hline Previous operation & $253(28.2 \%)$ & $234(27.9 \%)$ & $19(31.7 \%)$ & 0.533 \\
\hline Blood loss & 1124 mL (SD $1201 \mathrm{~mL}$ ) & $1113 \mathrm{~mL}$ (SD $1211 \mathrm{~mL})$ & 1276 mL (SD 1044 mL) & 0.868 \\
\hline Surgical time & $248 \min (\mathrm{SD} 100 \mathrm{~min})$ & $247 \min (\mathrm{SD} 99 \mathrm{~min})$ & $264 \min (\mathrm{SD} 123 \mathrm{~min})$ & 0.871 \\
\hline Cage & $378(42.0 \%)$ & $358(42.7 \%)$ & $20(32.7 \%)$ & 0.154 \\
\hline Number of levels fused & $3.2(\mathrm{SD} 2.9)$ & $3.2(\mathrm{SD} 2.9)$ & $3.3(\mathrm{SD} 2.5)$ & 0.190 \\
\hline Dural tear & $91(10.1 \%)$ & $82(9.8 \%)$ & $9(15.0 \%)$ & 0.197 \\
\hline Combined anterior approach & $25(2.8 \%)$ & $23(2.8 \%)$ & $2(3.4 \%)$ & 0.788 \\
\hline Smoking & $285(31.7 \%)$ & $265(31.6 \%)$ & $20(33.4 \%)$ & 0.738 \\
\hline Alcohol & $334(37.2 \%)$ & $305(36.4 \%)$ & $29(40.0 \%)$ & 0.268 \\
\hline Blood transfusion & $281(32.9 \%)$ & $257(32.2 \%)$ & $24(42.9 \%)$ & 0.101 \\
\hline Amount of transfusion & $279 \mathrm{~mL}(\mathrm{SD} 675 \mathrm{~mL})$ & $273 \mathrm{~mL}$ (SD $682 \mathrm{~mL}$ ) & $367 \mathrm{~mL}(572 \mathrm{~mL})$ & 0.638 \\
\hline Using NSAIDs preoperative & $442(48.2 \%)$ & $406(48.4 \%)$ & $36(60.0 \%)$ & 0.084 \\
\hline Timing antibiotics & $37 \min (\mathrm{SD} 20 \mathrm{~min})$ & $37 \min (\mathrm{SD} 19 \mathrm{~min})$ & $42 \min (\mathrm{SD} 22 \mathrm{~min})$ & 0.375 \\
\hline Mean fraction of inspired oxygen & 48.9 (SD 12) & 48.8 (SD 12) & 49.6 (SD 14.4) & 0.175 \\
\hline
\end{tabular}

*Trauma $=$ fracture with or without neurologic symptoms

Adult spinal deformity = kyphosis, juvenile scoliosis, adolescent scoliosis, neuromuscular scoliosis, idiopathic scoliosis, degenerative scoliosis, junctional kyphosis

One- or two-level degenerative spinal disorder with neurologic compromise = spondylolisthesis, spinale stenose, HNP

Failed back surgery syndrome $=$ pseudarthrosis, failed previous total disk replacement, previous laminectomy, discectomy, posterior fusion/anterior fusion, or hardware failure

One- or two-level degenerative spinal disorder without neurologic compromise $=$ degenerative disk disease, spondylosis, facet arthritis, adjacent segment degeneration

calibrated for the whole range of predicted probabilities, as it lies close to the 45-degree line of perfect fit.

The internal validation step yielded a shrinkage factor of 0.87 . All regression coefficients were multiplied by this factor to shrink them closer to 0 to produce less extreme predictions for future patients, to counteract the effect of model overfitting. 


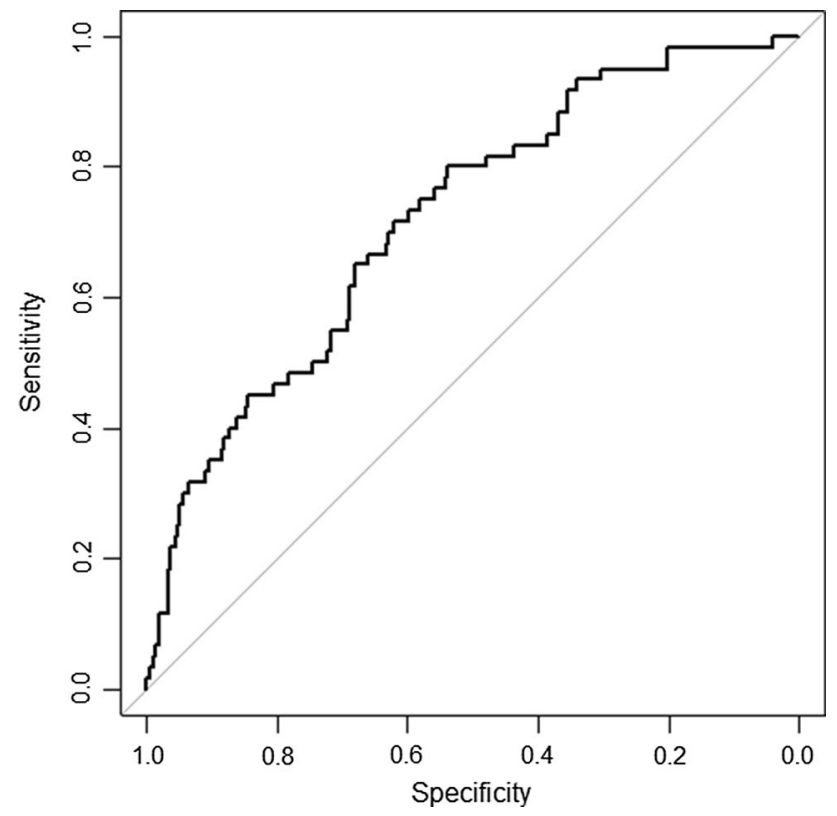

Fig. 1 Receiver operating characteristic curve of the prediction model for surgical site infection

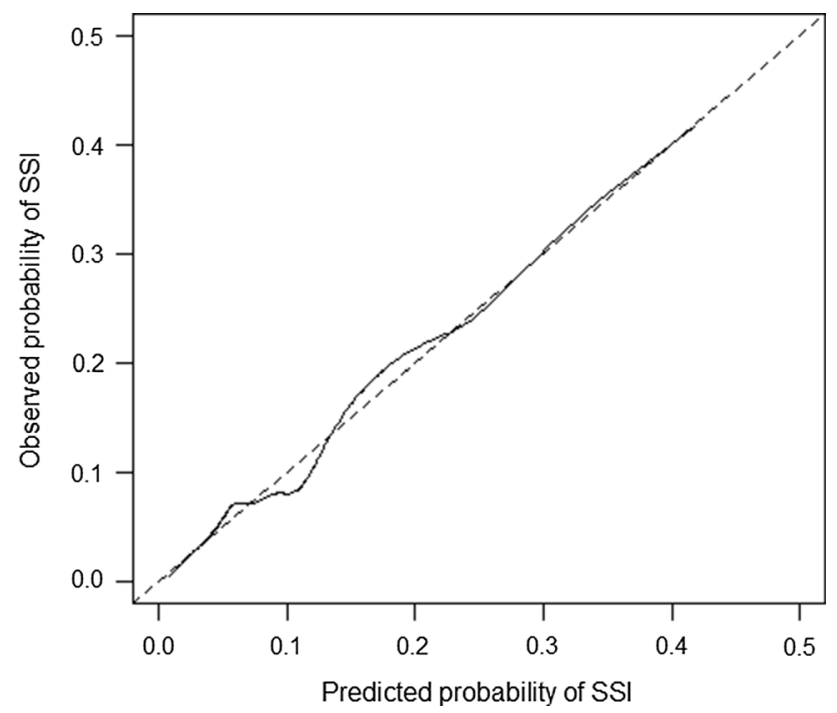

Fig. 2 Calibration plot of the prediction model for surgical site infection

\section{Prediction model}

Table 2 shows the coefficients of the resulting prediction model. The way to calculate an individual's risk of an SSI is shown in detail in Table 1.
Table 2 Prediction model for the occurrence of surgical site infection

\begin{tabular}{lrllc}
\hline Variable & $\begin{array}{l}\text { Regres- } \\
\text { sion coef- } \\
\text { ficient }\end{array}$ & $\begin{array}{l}\text { Odds ratio (95\% } \\
\text { CI }\end{array}$ & $p$ value & $\begin{array}{l}\text { Shrunk regres- } \\
\text { sion coefficient }\end{array}$ \\
\hline Intercept & -4.388 & - & - & -4.159 \\
Age & 0.016 & $1.01(1.00-1.04)$ & 0.100 & 0.014 \\
BMI 25-30 & -0.721 & $0.49(0.23-0.97)$ & 0.048 & -0.631 \\
Obese & 0.584 & $1.79(0.93-3.42)$ & 0.078 & 0.510 \\
ASA score & 0.600 & $1.82(1.22-2.74)$ & 0.004 & 0.524 \\
$\begin{array}{l}\text { Degen- } \\
\text { erative or }\end{array}$ & -0.661 & $0.52(0.29-0.92)$ & 0.023 & -0.578 \\
$\quad$ revision & & & & \\
NSAID use & 0.259 & $1.30(0.95-1.73)$ & 0.084 & 0.226 \\
\hline
\end{tabular}

${ }^{a}$ After adjustment for overfitting by shrinkage (shrinkage factor $=0.87$ ). The intercept was subsequently re-estimated

\section{Discussion}

This manuscript presents an internally validated predictive model to estimate the risk of SSI after instrumented thoracolumbar spinal fusion. In the literature, risk factors are generally reported as relative risks or odds ratios. Although these measures of association are important in understanding what contributes to an individual's probability of an SSI, they are difficult to translate into a tool for decision making and cannot be used to calculate an individual's probability of an SSI. The prediction model presented in this manuscript can be used to predict an individual risk (as a proportion or percentage) for SSI after instrumented spinal fusion.

This model may be helpful in the clinical setting to identify patients at high risk of SSI, optimizing patient selection and possibly prevent devastating consequences and associated outcomes of an SSI after surgery by extra preventive measures such as prolonged antibiotic prophylaxis or optimalization of nutritional status.

To our knowledge, this is the first prediction model for SSI after instrumented spine surgery procedures. The model has an AUC of 0.72 (95\% CI 0.65-0.79). This is considered to be moderate and is comparable to prediction models from other clinical disciplines with an AUC range from 0.54 to $0.73[22,23]$. Bear in mind that the model is used for prediction of future events, compared to diagnostic models that estimate the probability of the presence or absence of an outcome in the present time. Arguably, predicting the future is much more complex, like Niels Bohr said: "prediction is very difficult, especially about future."

Lee et al. presented a model for SSI in 2014 based on 1532 patients [12]. In the model of Lee et al., all spine surgery procedures were included, whereas in our model only instrumented procedures were included. A second difference between the two models was the definition of SSI. Lee et al. defined SSI as an infection requiring return to 
the operating room for irrigation and debridement without a clear difference between superficial and deep infection. Our definition of SSI was based on the CDC criteria and the Dutch national PREZIES network including only deep infections independent of return to the operating room.

One of the limitations of the model that we developed is the number of patients in our cohort. Although we used a large cohort consisting of 898 patients, more patients (and subsequently more cases of SSI) would have given us the opportunity to study even more potential predictor variables. Remarkably, some potential predictor variables that were important in other studies, like smoking and surgical invasiveness index, were not selected in our modeling procedure $[6,13]$. This could be due to a lack of statistical power, also related to the number of patients in our cohort. Other risk factors described in the literature with a very low incidence in our cohort, like Parkinson's disease and paraplegia, were not selected [24].

Some other associations between predictor variables and SSI were unexpected $[25,26]$ : We did not observe a linear association between BMI and the log-odds of an SSI. Overweight patients with a BMI between 25 and 30 were more protected for SSI compared to normal weight (BMI 20-25), but obese and morbidly obese patients with a BMI of more than 30 were more prone to an SSI after instrumented spine surgery. In most literature, only (morbid) obesity (BMI > 30) is described as risk factor for SSI after spine surgery although overweight patients with a BMI less than 30 were not described as a risk factor [7, 13, 27]. A hypothesis for mild overweight as a protective factor could be that these patients have more soft tissue covering of the instrumentation after an instrumented spinal procedure.

Most predictive variables were in agreement with the literature. Age, ASA score, and diagnosis were significant risk factors for SSI in our model. In the previous literature, patients with comorbid medical conditions were found to be significantly associated with SSI [7, 28, 29]. Trauma, adult spinal deformity with long segment procedures, spondylodiscitis and malignancy had a higher risk for SSI than degenerative or failed back surgery syndrome [6, 30-33]. Also older age had an increased risk of postoperative spinal infection $[13,34]$.

Although this model can be of great benefit when considering risk assessment, it would be most valuable if it was generalizable to future patients and patients from different hospitals. Hence, it should be externally validated to assess how the prediction model performs in patients sampled independently from the derivation cohort.

\section{Conclusion}

We presented an internally validated predictive model for SSI after instrumented thoracolumbar spine surgery. This tool can be of substantial value in the preoperative counseling of patients for shared surgical decision making and ultimately improve safety in spine surgery. Identification of patients at risk for postoperative infection allows for individualized patient risk assessment with better patient-specific counseling and may accelerate the implementation of multidisciplinary strategies for the reduction of SSIs.

\section{Compliance with ethical standards}

Conflict of interest All authors declare that they have no conflict of interest.

OpenAccess This article is distributed under the terms of the Creative Commons Attribution 4.0 International License (http://creativecommons.org/licenses/by/4.0/), which permits unrestricted use, distribution, and reproduction in any medium, provided you give appropriate credit to the original author(s) and the source, provide a link to the Creative Commons license, and indicate if changes were made.

\section{References}

1. Godil SS, Parker SL, O’Neill KR, Devin CJ, McGirt MJ (2013) Comparative effectiveness and cost-benefit analysis of local application of vancomycin powder in posterior spinal fusion for spine trauma: clinical article. J Neurosurg Spine 19:331-335. https:// doi.org/10.3171/2013.6.SPINE121105

2. Stone PW (2009) Economic burden of healthcare-associated infections: an American perspective. Expert Rev Pharmacoecon Outcomes Res 9:417-422. https://doi.org/10.1586/erp.09.53

3. Janssen DMC, Kramer M, Geurts J, Rhijn LV, Walenkamp G, Willems PC (2018) A retrospective analysis of deep surgical site infection treatment after instrumented spinal fusion with the use of supplementary local antibiotic carriers. J Bone Joint Infect 3:94-103. https://doi.org/10.7150/jbji.23832

4. Haddad S, Nunez-Pereira S, Pigrau C, Rodriguez-Pardo D, VilaCasademunt A, Alanay A, Acaroglu ER, Kleinstueck FS, Obeid I, Perez-Grueso FJS, Pellise F, European Spine Study G (2018) The impact of deep surgical site infection on surgical outcomes after posterior adult spinal deformity surgery: a matched control study. Eur Spine J 27:2518-2528. https://doi.org/10.1007/s0058 6-018-5583-3

5. Tsubouchi N, Fujibayashi S, Otsuki B, Izeki M, Kimura H, Ota M, Sakamoto T, Uchikoshi A, Matsuda S (2018) Risk factors for implant removal after spinal surgical site infection. Eur Spine J 27:2481-2490. https://doi.org/10.1007/s00586-017-5294-1

6. Schimmel JJ, Horsting PP, de Kleuver M, Wonders G, van Limbeek J (2010) Risk factors for deep surgical site infections after spinal fusion. Eur Spine J 19:1711-1719. https://doi.org/10.1007/ s00586-010-1421-y

7. Fang A, Hu SS, Endres N, Bradford DS (2005) Risk factors for infection after spinal surgery. Spine 30:1460-1465

8. Sierra-Hoffman M, Jinadatha C, Carpenter JL, Rahm M (2010) Postoperative instrumented spine infections: a retrospective 
review. South Med J 103:25-30. https://doi.org/10.1097/ SMJ.0b013e3181c4e00b

9. Fang XT, Wood KB (2013) Management of postoperative instrumented spinal wound infection. Chin Med J 126:3817-3821

10. Chen SH, Lee CH, Huang KC, Hsieh PH, Tsai SY (2015) Postoperative wound infection after posterior spinal instrumentation: analysis of long-term treatment outcomes. Eur Spine J 24:561570. https://doi.org/10.1007/s00586-014-3636-9

11. Hegde V, Meredith DS, Kepler CK, Huang RC (2012) Management of postoperative spinal infections. World J Orthop 3:182189. https://doi.org/10.5312/wjo.v3.i11.182

12. Lee MJ, Cizik AM, Hamilton D, Chapman JR (2014) Predicting surgical site infection after spine surgery: a validated model using a prospective surgical registry. Spine J 14:2112-2117. https://doi. org/10.1016/j.spinee.2013.12.026

13. Wang T, Wang H, Yang DL, Jiang LQ, Zhang LJ, Ding WY (2017) Factors predicting surgical site infection after posterior lumbar surgery: a multicenter retrospective study. Medicine (Baltimore) 96:e6042. https://doi.org/10.1097/MD.000000000000604

14. Hu X, Lieberman IH (2018) Revision spine surgery in patients without clinical signs of infection: how often are there occult infections in removed hardware? Eur Spine J. https://doi. org/10.1007/s00586-018-5654-5

15. Janssen DMC, van Kuijk SMJ, d'Aumerie BB, Willems PC (2018) External validation of a prediction model for surgical site infection after thoracolumbar spine surgery in a Western European cohort. J Orthop Surg Res 13:114. https://doi.org/10.1186/s1301 8-018-0821-2

16. Mangram AJ, Horan TC, Pearson ML, Silver LC, Jarvis WR (1999) Guideline for prevention of surgical site infection, 1999. Hospital Infection Control Practices Advisory Committee. Infect Control Hosp Epidemiol 20:250-278. https://doi. org/10.1086/501620

17. Geubbels EL, Mintjes-de Groot AJ, van den Berg JM, de Boer AS (2000) An operating surveillance system of surgical-site infections in The Netherlands: results of the PREZIES national surveillance network. Preventie van Ziekenhuisinfecties door Surveillance. Infect Control Hosp Epidemiol 21:311-318. https://doi. org/10.1086/501762

18. Peduzzi P, Concato J, Kemper E, Holford TR, Feinstein AR (1996) A simulation study of the number of events per variable in logistic regression analysis. J Clin Epidemiol 49:1373-1379

19. Mirza SK, Deyo RA, Heagerty PJ, Turner JA, Lee LA, Goodkin $R$ (2006) Towards standardized measurement of adverse events in spine surgery: conceptual model and pilot evaluation. BMC Musculoskelet Disord 7:53. https://doi.org/10.1186/1471-2474-7-53

20. Ament R (1979) Origin of the ASA classification. Anesthesiology $51: 179$

21. Harrell FE (2001) Regression modeling strategies. Springer, Berlin

22. Folkert MR, Setton J, Apte AP, Grkovski M, Young RJ, Schoder H, Thorstad WL, Lee NY, Deasy JO, Oh JH (2017) Predictive modeling of outcomes following definitive chemoradiotherapy for oropharyngeal cancer based on FDG-PET image characteristics. Phys Med Biol 62:5327-5343. https://doi.org/10.1088/1361-6560/ aa73cc

23. Meertens LJE, van Montfort $P$, Scheepers HCJ, van Kuijk SMJ, Aardenburg R, Langenveld J, van Dooren IMA, Zwaan IM, Spaanderman MEA, Smits LJM (2018) Prediction models for the risk of spontaneous preterm birth based on maternal characteristics: a systematic review and independent external validation. Acta Obstet Gynecol Scand. https://doi.org/10.1111/aogs.13358

24. McClelland S 3rd, Baker JF, Smith JS, Line BG, Errico TJ, Ames CP, Bess RS (2017) Impact of Parkinson's disease on perioperative complications and hospital cost in multilevel spine fusion: a population-based analysis. J Clin Neurosci 35:88-91. https://doi. org/10.1016/j.jocn.2016.10.008

25. Jeffcoach DR, Sams VG, Lawson CM, Enderson BL, Smith ST, Kline H, Barlow PB, Wylie DR, Krumenacker LA, McMillen JC, Pyda J, Daley BJ, University of Tennessee Medical Center DoS (2014) Nonsteroidal anti-inflammatory drugs' impact on nonunion and infection rates in long-bone fractures. J Trauma Acute Care Surg 76:779-783. https://doi.org/10.1097/TA.0b013e3182aafe0d

26. den Broeder AA, Creemers MC, Fransen J, de Jong E, de Rooij DJ, Wymenga A, de Waal-Malefijt M, van den Hoogen FH (2007) Risk factors for surgical site infections and other complications in elective surgery in patients with rheumatoid arthritis with special attention for anti-tumor necrosis factor: a large retrospective study. J Rheumatol 34:689-695

27. Koutsoumbelis S, Hughes AP, Girardi FP, Cammisa FP Jr, Finerty EA, Nguyen JT, Gausden E, Sama AA (2011) Risk factors for postoperative infection following posterior lumbar instrumented arthrodesis. J Bone Joint Surg Am 93:1627-1633. https://doi. org/10.2106/JBJS.J.00039

28. Pesenti S, Pannu T, Andres-Bergos J, Lafage R, Smith JS, Glassman S, de Kleuver M, Pellise F, Schwab F, Lafage V, Scoliosis Research S (2018) What are the risk factors for surgical site infection after spinal fusion? A meta-analysis. Eur Spine J 27:24692480. https://doi.org/10.1007/s00586-018-5733-7

29. Tominaga H, Setoguchi T, Ishidou Y, Nagano S, Yamamoto T, Komiya S (2016) Risk factors for surgical site infection and urinary tract infection after spine surgery. Eur Spine J 25:3908-3915. https://doi.org/10.1007/s00586-016-4674-2

30. Atkinson RA, Stephenson J, Jones A, Ousey KJ (2016) An assessment of key risk factors for surgical site infection in patients undergoing surgery for spinal metastases. J Wound Care 25(Suppl 9):S30-S34. https://doi.org/10.12968/jowc.2016.25.Sup9.S30

31. Kumar S, van Popta D, Rodrigues-Pinto R, Stephenson J, Mohammad S, Siddique I, Verma RR (2015) Risk factors for wound infection in surgery for spinal metastasis. Eur Spine J 24:528-532. https://doi.org/10.1007/s00586-013-3127-4

32. Lai Q, Song Q, Guo R, Bi H, Liu X, Yu X, Zhu J, Dai M, Zhang B (2017) Risk factors for acute surgical site infections after lumbar surgery: a retrospective study. J Orthop Surg Res 12:116. https:// doi.org/10.1186/s13018-017-0612-1

33. Saeedinia S, Nouri M, Azarhomayoun A, Hanif H, Mortazavi A, Bahramian P, Yarandi KK, Amirjamshidi A (2015) The incidence and risk factors for surgical site infection after clean spinal operations: a prospective cohort study and review of the literature. Surg Neurol Int 6:154. https://doi.org/10.4103/2152-7806.166194

34. Chaichana KL, Bydon M, Santiago-Dieppa DR, Hwang L, McLoughlin G, Sciubba DM, Wolinsky JP, Bydon A, Gokaslan ZL, Witham T (2014) Risk of infection following posterior instrumented lumbar fusion for degenerative spine disease in 817 consecutive cases. J Neurosurg Spine 20:45-52. https://doi. org/10.3171/2013.10.SPINE1364 


\section{Affiliations}

Daniël M. C. Janssen ${ }^{1}$ (D) Sander M. J. van Kuijk ${ }^{1} \cdot$ Boudewijn d'Aumerie $^{1} \cdot$ Paul Willems $^{1}$

$\triangle$ Daniël M. C. Janssen

dmc.janssen@alumni.maastrichtuniversity.nl

Sander M. J. van Kuijk

sander.van.kuijk@mumc.nl

Boudewijn d'Aumerie

boudewijn.aumerie@gmail.com
Paul Willems

p.willems@mumc.nl

Department of Orthopaedic Surgery, Research School CAPHRI, Maastricht University Medical Center, P.

Debyelaan 25, 6229 HX Maastricht, The Netherlands 